Дата: поступления статьи: 20.01.2021

после рецензирования: 03.03.2021

принятия статьи: 01.04.2021

\title{
С.А. Голубков
}

Самарский национальный исследовательский университет имени академика С.П. Королева, г. Самара, Российская Федерация

E-mail: golubkovsa@yandex.ru

ORCID: https://orcid.org/0000-0003-3423-1520

\section{Понятия «современное», «новое» и «своевременное» в литературном сознании 1920-х годов}

Аннотация: в данной статье идет речь о том, как время радикальных перемен трансформирует литературную ситуацию, меняет само содержание современности. В это содержание входит смена типов художественного мышления, взаимодействие стилевых тенденций, возникновение актуальной тематики, смена самих форм бытования литературного произведения, изменение писательского статуса в социуме, рождение новых читательских запросов. Литературная современность рассматривается как поливекторный процесс, в который включаются различные творческие группы, писательские сообщества. Они предлагают свои инновации. Существо новизны очередной эпохи может выражаться в активном споре с предшествующими литературными моделями. Современники могут вкладывать в понятие новое разное содержание. Так, в чрезвычайно политизированные 1920-е годы черты нового могла вдруг приобрести ориентация не на идеологическую доминанту творчества, а на талант художника, на эстетическое качество его творческого продукта, на обновление художественных форм («Серапионовы братья», «Перевал»). Под новым понимали варианты плодотворного синтеза фантастики и быта, реализма и символизма, реализма и экспрессионизма, точечной конкретики и широкого абстрагирования. Рассматривались судьбы отдельных жанров (например, романа). Новое могло проявиться и в самом понимании своевременности (актуальности) литературного произведения. С постепенным введением жесткой регламентации в литературный процесс менялось понимание такой актуальности (теория социального заказа). Неочевидность нового (скрытая своевременность) позволяет подвергать литературу 1920-х годов переоценкам, посмотреть на нее с вековой дистанции. Обнаруживаются подлинные инновации этого времени.

Ключевые слова: современное, новое (инновация), своевременное, поливекторный процесс, синтез, идеологический диктат, регламентация, социальный заказ, запрос эпохи, неочевидное, скрытая своевременность.

Цитирование: Голубков С.А. Понятия «современное», «новое» и «своевременное» в литературном сознании 1920-х годов // Семиотические исследования. Semiotic studies. 2021. T. 1, № 1. C. 42-48. DOI: http://doi.org/10.18287/2782-2966-2021-1-1-42-48.

Благодарности: автор статьи выражает признательность литературоведам Самарского университета - организаторам Всероссийской конференции с международным участием «Современное» как проблема в истории литературы и культуры (слова и границы понятий: «модерн», «модернизм», «постмодерн», «постмодернизм»), посвященной 75-летию доктора филологических наук профессора Николая Тимофеевича Рымаря, за создание атмосферы творческого диалога, побуждающего к продуктивным размышлениям.

Информация о конфликте интересов: автор заявляет об отсутствии конфликта интересов.

(C) Голубков С.А., 2021 - доктор филологических наук, профессор, кафедра русской и зарубежной литературы и связей с общественностью, Самарский национальный исследовательский университет имени академика С.П. Королева, 443086, Российская Федерация, г. Самара, Московское шоссе, 34. 


\title{
S.A. Golubkov
}

Samara National Research University, Samara, Russian Federation

E-mail: golubkovsa@yandex.ru

ORCID: https://orcid.org/0000-0003-3423-1520

\section{The concepts «modern», «new» and «timely» in the literary consciousness of the 1920s}

\begin{abstract}
: in this article, we are talking about how the time of radical changes transforms the literary situation, changes the very content of modernity. This content includes a change in the types of artistic thinking, the interaction of style trends, the emergence of relevant topics, the change in the very forms of existence of a literary work, the change in the writer's status in society, the birth of new reader requests. Literary modernity is considered as a polyvector process, which includes various creative groups and writing communities. They offer their own innovations. The essence of the novelty of the next epoch can be expressed in an active dispute with the previous literary models. Contemporaries can put different content into the concept of a new one. So, in a highly political 1920-ies features of the new could suddenly acquire focus not on the ideological dominance of creativity and talent on the aesthetic quality of its products, to update the art forms («Serapion's brothers», «Pass»). Under the new one, we understood the variants of a fruitful synthesis of fiction and everyday life, realism and symbolism, realism and expressionism, point specifics and broad abstraction. The fate of individual genres (for example, the novel) was considered. The new could manifest itself in the very understanding of the timeliness (relevance) of a literary work. With the gradual introduction of strict regulation in the literary process, the understanding of such relevance changed (the theory of social order). The non-obviousness of the new (hidden timeliness) allows us to reevaluate the literature of the 1920 s, to look at it from a century-old distance. The true innovations of this time are revealed.

Key words: modern, new (innovation), timely, polyvector process, synthesis, ideological dictate, regulation, social order, request of the epoch, non-obvious, hidden timeliness.

Citation: Golubkov, S.A. (2021), The concepts «modern», «new» and «timely» in the literary consciousness of the 1920s, Semioticheskie issledovanija. Semiotic studies, vol. 1, no. 1, pp. 42-48, DOI: http://doi.org/10.18287/2782-2966-2021-1-1-42-48

Acknowledgements: the author of the article expresses his gratitude to the literary critics of Samara University - the organizers of the All-Russian Conference with international participation «Modern Art» as a problem in the history of literature and culture (words and boundaries of concepts: «modern», «modernism», «postmodern», «postmodernism»), dedicated to the 75th anniversary of the Doctor of Philology (habilitatus), Professor Nikolai Timofeevich Rymar, for creating an atmosphere of creative dialogue that encourages productive reflection.

Information about conflict of interests: the author declares no conflict of interests.

(C) Golubkov S.A., 2021 - Dr. philol. habil., Professor, Department of Russian and Foreign Literature and Public Relations, Samara National Research University, 34, Moskovskoe Shosse (St.), Samara, 443086, Russian Federation.
\end{abstract}

\section{Введение}

Время многомерно. Существует несколько временных измерений, в которых существует человек. Наряду с временем физическим, объективно существующим, у каждого из нас есть индивидуальное психологическое время. У каждой цивилизации есть свое цивилизационное время, движение которого измеряется событийной и смысловой наполненностью процесса развития социума. Эти времена могут не совпадать. Кроме того, существуют разные парадигмы толкования большого времени бытия человечества: разомкнуто-линейная (теория поступательного прогресса) и циклически-замкнутая (теория О. Шпенглера).

Ментально-эмоциональное восприятие человеком времени (психологическое время) тоже не- линейно. Оно парадоксально соединяет в себе, с одной стороны, случайностную мозаичность, а с другой стороны, иерархичность, поскольку включает разные свои уровни: мироощущение, миропонимание, мироотношение. Мироощущение в известной степени стихийно, оно связано с интуитивно-чувственным восприятием времени. Миропонимание, так сказать, располагается в плоскости логического объяснения событий и примет протекающей временной действительности, занято поиском скрытых причинно-следственных связей. И, наконец, мироотношение знаменует действенное отношение ко времени, провоцирует человека на поступок.

И объективно-физическое, и цивилизационное, и психологическое время имеют макро- и ми- 
кроединицы своего измерения (эпохи, процессы, этапы, события, поступки, впечатления, душевные импульсы). Отношение ко времени в разные исторические эпохи было разным. Время нередко трактовалось как неизменность. А там, где неизменность, там нет и понятия современности, ощущения прихода чего-то совершенно нового. Д.С. Лихачев в книге «Поэтика древнерусской литературы» писал по этому поводу: «Люди замечают то, что движется, и не видят неподвижного. Заметить движение - это значит заметить и движущийся объект. Это же касается и изменений во времени. В самом деле, если мы присмотримся к тому, как понимался мир в античности или в средневековье, то заметим, что современники многого не замечали в этом мире, и это происходило потому, что представления об изменяемости мира во времени были сужены. Социальное и политическое устройство мира, быт, нравы людей и многое другое казались неизменными, навеки установленными. Поэтому современники их не замечали и их не описывали в литературных и исторических сочинениях. Летописцы и хроникеры отмечают лишь события, происшествия в широком смысле этого слова. Остального они не видят. Категория времени имеет все большее и большее значение в современном понимании мира и в современном отражении этого мира в искусстве» (Лихачев 1979 , с. 209).

\section{Ход исследования}

Слова «современное» и «сегодняшнее» обычно трактуются как синонимы. В известной степени это правильно. Различие этих понятий состоит в масштабе смыслового поля. Сегодняшнее у́же, современное шире. Говоря об их семантике, мы используем, как правило, хронологический аспект в своих рассуждениях. Когда же речь заходит о более глубоком их различении, человек обращается уже к аспекту идейно-содержательному.

Евгений Замятин так писал об этих понятиях: «..."сегодняшнее" и "современное" - величины разных измерений; у "сегодняшнего" - практически - нет измерения во времени, оно умирает завтра, а "современное" - живет во временных масштабах эпохи. Сегодняшнее - жадно цепляется за жизнь, не разбирая средств: надо торопиться жить только до завтра. И отсюда в сегодняшнем непременная юркость, угодливость, легковесность, боязнь копнуть на вершок глубже, боязнь увидать правду голой. Современное - стоит над сегодня, оно может с ним диссонировать, оно может оказаться (или показаться) близоруким - потому что оно дальнозорко, оно смотрит вдаль. От эпохи - сегодняшнее берет только окраску, кожу, это закон мимикрии; современному - эпоха передает сердце и мозг, это закон наследственности» (Замятин 1988, с. 445).
Заметим так-же, что любая современность это поливекторный процесс, ведь речь идет о включении в одномоментно протекающий жизненный поток разновозрастных наций, обществ, людей, культур. Можно вспомнить давние литературоведческие и педагогические споры 1970-х гг. о сложностях, возникавших при преподавании литературы народов СССР (материалы публиковались в №№ 3, 10 журнала «Вопросы литературы» за 1977 год). Единый литературный процесс с трудом выстраивался, поскольку в общее движение вовлекались и древние письменные, и младописьменные литературы. В силу исторических обстоятельств у них были разная стадиальность, разный капитал традиций, различная по сохранности фольклорная база как резервуар архетипов мифологического сознания.

Толкование современного применительно к художественной литературе предполагает, конечно, и наличие разных измерительных инструментов оценивания, позволяющих обнаружить смену типов художественного мышления, взаимодействие стилевых тенденций, возникновение актуальной тематики, смену самих форм бытования литературного произведения, изменение писательского статуса в социуме, рождение новых читательских запросов.

Существо новизны очередной литературной эпохи может выражаться в активном споре с предшествующими литературными моделями. Как отмечает Б. Гройс, «инновация не состоит в создании чего-то нового, чего не было в мире прежде - на такую инновацию способен только Творец мира, но не смертный человек. Для человека инновация возможна только как переоценка ценностей, как смещение границы между культурными ценностями и профанными вещами» (Гройс, с.150). В таком творческом диалоге с существующими в культурном архиве художественными моделями можно выделить два принципиально важных аспекта: 1) внешний, вербально реализуемый в громких декларациях, широковещательных манифестах той или иной литературной группы; 2) внутренний, ознаменованный подспудными внутрилитературными процессами, связанными с рождением нового художественного языка, с жанровыми трансформациями (например, возникновение антижанра, той же антиутопии).

Такая инновация связана также с отношением ко времени, к пониманию современности как непрекращающегося процесса культурного обмена, процесса творческого обновления, касающегося всего корпуса социокультурных идей и построений. Б.А. Ланин в статье «Анатомия литературной антиутопии» отмечал это стремление ускорить время, приблизить новое, современное: «Антиутопия всегда проникнута ощущением 
застывшего времени, поэтому авторский пафос в «поторапливании» времени. Испортилась Часовая Скрижаль в Едином Государстве, застыло время в Чевенгуре, задремало - в «Приглашении на казнь». Время всегда кажется антиутопии слишком замедлившим свой бег. Отсюда - непременная попытка заглянуть в будущее, «логически» - сообразно авторской, а не всегда художественной логике - продолжить, «дописать» историю, заглянуть в завтрашний день, но при этом закамуфлировать скачок во времени» (Ланин, с. 161).

Современное как понятие, конечно, связано с понятием нового. Современные ученые в своих монографиях и сборниках научных трудов исследуют, как происходит становление нового в каждую литературную эпоху. Назовем коллективный труд сотрудников Института мировой литературы РАН «В поисках новой идеологии: Социокультурные аспекты русского литературного процесса 1920-1930-х годов», вышедший под редакцией О.А.Казниной в 2010 году (В поисках новой идеологии... 2010).

Естественно, современники могут вкладывать в понятие новое разное содержание. Так, в 1920-е годы черты нового могла вдруг приобрести ориентация не на идеологическую доминанту творчества, а на талант художника, на эстетическое качество его творческого продукта. Примечательна в этом отношении группа «Перевал». Литературовед Г.А. Белая назвала свою монографию об истории этой литературной группы весьма примечательно - «Дон-Кихоты 20-х годов: «Перевал» и судьба его идей» (Белая 1989). Донкихотство А.К. Воронского и его группы, по мысли автора книги, заключалось в том, что в условиях жесточайшей идеологической борьбы и возобладавших вульгарно-социологических тенденций делать ставку на литературный талант, духовную свободу художника и чисто эстетические критерии было делом неосуществимым и в известном смысле безрассудным. Во главу угла «перевальцы» ставили не социальную принадлежность писателя, а богатство его художественного мира. Они справедливо полагали, что любые мертвящие вульгарно-социологические схемы ведут к обескровливанию и обеднению искусства.

В литературе 1920-х годов под новым понимали и варианты плодотворного синтеза фантастики и быта, реализма и символизма, реализма и экспрессионизма, точечной конкретики и широкого абстрагирования (что видно по творчеству писателей группы «Серапионовы братья»). Правда, это длилось недолго, вскоре наступило новое десятилетие, когда литературу бесцеремонно бросили на «прокрустово ложе» административно «спущенного сверху» соцреализма.

Современники могли соотносить новое и с судьбами либо всей сложившейся жанровой си- стемы, либо одного жанра. Характерна в этом отношении статья О. Мандельштама «Конец романа», опубликованная в первом номере альманаха «Паруса» за 1922 год. Рассматривая роман как жанр, измеряемый «биографической мерой», автор статьи давал прогноз: «Дальнейшая судьба романа будет не чем иным, как историей распыления биографии как формы личного существования, даже больше чем распыления - катастрофической гибели биографии» (Мандельштам 2003, c. 94). Отмечая, что «ныне европейцы выброшены из своих биографий», О. Мандельштам признает: «Человек без биографии не может быть тематическим стержнем романа, и роман, с другой стороны, немыслим без интереса к отдельной человеческой судьбе, - фабуле и всему, что ей сопутствует» (Мандельштам 2003, с. 95). История литературного развития показала в дальнейшем, что роман не «кончился», а радикально обновился, подвергся сложным трансформациям, приобрел новые качества. Оценивая развитие европейского романа 1920-х годов, Н.Т. Рымарь обнаруживает характерную черту этого процесса в том, что «роман 20-х годов рвет с той относительной завершенностью произведения романного искусства XIX века, которое обладало своей автономностью по отношению к потоку жизни: роман XIX века был в непосредственном контакте с современной действительностью, но это был контакт, который мыслился как ее отражение, роман строился как зеркало жизни, отражающее ее во всем ее богатстве и всей ее противоречивости» (Рымарь 2001, с. 23). Действительно, роман как жанр стал жить другой жизнью. Возникали новые экспериментальные модификации романа. К их числу можно отнести, кстати, книгу Артема Веселого «Россия, кровью умытая», над которой писатель работал в 1930-е годы.

Разумеется, само понимание нового исторически изменчиво. Борис Гройс в работе «О новом» писал: «Особенность понимания нового, получившего распространение в Новое время, состоит в ожидании того, что в конце концов появится нечто настолько новое, что после него ничего новее быть не может - лишь бесконечное господство этого наипоследнего нового над будущим» (Гройс 1993, c. 113).

Таким образом, в понимании нового есть две грани - поверхностная и глубинная. С этим наличием двух сторон связана и известная иллюзорность нового. Мы порой поверхностно-новое принимаем за глубинно-новое, хотя в этом глубинном ничего не меняется и не происходит. Меняется поверхностность жизни (названия учреждений и социальных институтов, моды, технологии, бытовые реалии, литературные темы, словесный обиход), но меняется ли при этом глубинная суть жизни?

Таким образом, в современности может заключаться и немалый компонент мнимости. Люди в 
какой-то степени оказываются заложниками, пленниками ожидаемого. Смысловое пространство культурного кода отечественной литературы, изобилующее чрезвычайно значимыми мифологемами, идеологемами, символами, концептами и мотивами, закономерно включает и этот мотив мнимости.

Современник, живущий в эпоху радикального слома привычных ценностных парадигм, вынужден постоянно решать задачу снятия противоречия между кажимостью и действительностью любого явления, попадающего в сферу его внимания. В этом отношении весьма показателен двадцатый век - век исторических потрясений, разломов, рубежей. Исторический маятник раскачивался от полюса тотальной анархии к полюсу тотальной регламентации жизни. С одной стороны, наблюдается своеобразное литературное «хулиганство» как крайняя форма выражения свободы творчества (Поварницына 2009). С другой стороны, жесткая идеологизация литературы, замена естественного запроса (на новую тему, нового героя, новый жанр), вызревающего исподволь в глубинах эпохи, на откровенно декретируемый социальный заказ, прямолинейно трактующий обязательную своевременность литературного продукта.

Отныне характеристика современности просто не могла обойтись без понятия своевременное. Конечно, разные группы реципиентов вкладывали в него разные смыслы - политические, социальные, этические, эстетические. Известная нескольким поколениям советских школьников давняя ленинская оценка книги Горького «Мать» как «очень своевременной» (высказана в самом начале XX века) имела, как мы знаем, узко прагматический, чисто сиюминутно-политический смысл, а никак не эстетический. Все зависело от пресловутого горизонта ожидания реципиента, от выстраиваемой им предварительной системы ценностных координат. Слово «своевременное» приходит в наше сознание с цепочкой синонимов: актуальный, злободневный, сущностный, животрепещущий, наболевший, назревший. Рубрика в газете «Новая жизнь» 1917-1918 гг, где печатались статьи-рассуждения М. Горького (Горький 1990), по сути была сугубо полемически названа - «Несвоевременные мысли», ведь любая мысль так или иначе своевременна, поскольку открывает какие-то грани действительности (тем более в высшей степени своевременными были тревожные мысли-предостережения М. Горького по поводу жестокого разгула новой власти).

Между тем в 1920-е годы слово «своевременное» было в ходу, оно часто мелькает на страницах литературных журналов и в публицистике того времени. Так, Ю.Н. Тынянов в статье «Русская литература современности» делал особый акцент на этом понятии, рассматривая его как примету эпохи написания статьи: «Нынче каждое произведение либо "необходимое", либо "ненужное", а не просто "интересное" или "неинтересное", и потому нам безразлично, "хорошо" или "плохо" сделана работа, хорош или плох язык автора, важно совсем другое: чтобы работа была живой, чтобы правильно было схвачено "необходимое"» (Тынянов 1995-1996, с. 93).

М.О. Чудакова в своих работах неоднократно писала о том, что регламент как система запретов и ограничений в течение первого советского десятилетия достаточно сложно соотносился с представлением о «социальном заказе». Многие литераторы вполне искренне были озабочены ощущением нужности или ненужности своей работы. Надо заметить, что понятие социального заказа неоднозначно воспринимали сами писатели и критики 1920-х годов, о чем, скажем, свидетельствует статья Вяч. Полонского «О теории социального заказа» (Опыт неосознанного поражения 2001, с. 351-354).

Писатели по-разному реагировали на эти идеологические тиски. Один из организаторов литературной группы «Серапионовы братья» Лев Лунц, например, считал художника свободным от коллективной, «спущенной сверху» идеологии: «Но не следует забывать, что роман без точного и ясного «миросозерцания» может быть прекрасным, роман же из одной только голой идеологии - невыносим» (Опыт неосознанного поражения 2001, c.106). Желая уйти от прямолинейного идеологического диктата, писатели прибегали к художественным шифрам, усложненному образному языку, к различным формам условности. Так, для писателя Сигизмунда Кржижановского афоризм как сверхмалый (вернее, минимальный) жанр приобрел функцию специфического зеркальца, в котором парадоксально отразился повседневный лик эпохи исторических метаморфоз. «У нас часто путают властителей дум с блюстителями дум» (Кржижановский 2010, с. 321); «У нас слаще всех живется Горькому, а богаче всех Бедному» (Кржижановский 2010, с. 385). Творческое инословие С. Кржижановского (буквализация метафор, игра в алогизмы, ироническая парадоксализация отображаемого) было специфическим способом самостоятельного, подчеркнуто индивидуального речевого поведения, противостоящего тому официозному советскому новоязу, который включал в себя набор безликих бюрократических штампов, лозунговых стереотипов. Такой же речевой формой писательской автономизации было и странноязычие Андрея Платонова.

Следует сказать и о такой черте нового в структуре современности, как его неочевидность. Оно 
не сразу обнаруживается, не сразу «проступает» со всеми своими характеристическими чертами и подробностями подобно тому, как постепенно возникает фотоизображение в старой кювете с проявителем. Есть сфера так называемых «прописных» истин, декларативных сентенций, зримых смыслов, лежащих на поверхности бытия. Если бы наша интеллектуальная жизнь только этим и ограничивалась, мы были бы в духовном плане чрезвычайно бедны. Но, к счастью, есть и огромная область неочевидного, далеко не сразу открывающаяся даже весьма внимательному наблюдателю. К числу первооткрывателей тех таинственных реалий, что составляют такую область, безусловно, относился в литературе рубежа XIX-XX вв. Антон Павлович Чехов, писатель, совершенно свободный от декларативного проповедничества, откровенного дидактизма и назидательного морализаторства. Писатель, многое предвосхитивший в наступившем столетии.

Современность уникальна, и в этом отношении актуален вопрос о возможности / невозможности сопоставления разных литературных (и шире культурных) эпох.

Скрытая своевременность литературных открытий, подлинный масштаб которой мог быть обнаружен не сразу, а значительно позднее, заключался в ориентации на тот или иной художественный опыт писателей-предшественников. Так, М.О. Чудакова писала о влиянии прозы И. Бунина на литераторов советского времени: «Его проза дала импульс тем, кто пошел мимо психологического анализа («под Толстого») и бытописи - того, что стало дорогой официозной, старательно соблюдавшей требования регламента, прозы. Связь с Буниным очевидна у тех, кто обозначил линию неофициальной литературы (во главе ее встал Паустовский)» (Чудакова 2007, с. 29).

В каждом новом явлении есть своя ограниченность, любое конкретное декларируемое новое не бесконечно.

\section{Заключение}

Мерцающее в дымке грядущего Новое неразличимо. И это еще один аспект проблемы. Мы просто можем не узнать это Новое. Реальное Новое может опровергнуть наши робкие прогнозы. Новое может быть не там и не в том, что мы предполагаем. В этом и заключена жгучая интрига перехода от настоящего к будущему. Рассмотрение культурных процессов глазами человека XXI века, со столетней дистанции, позволяет увидеть, что именно оказалось новым и своевременным, что составило подлинное существо тогдашней современности. Отпала шелуха мнимых инноваций, вроде претензий вульгарного социологизма на культурную монополию, а осталось отнюдь не то, что было «на слуху» в те далекие годы.

\section{Библиографический список}

Белая Г.А. Дон-Кихоты 20-х годов: «Перевал» и судьба его идей. Москва: Советский писатель, 1989. $400 \mathrm{c}$.

В поисках новой идеологии: Социокультурные аспекты русского литературного процесса 19201930-х годов / отв. ред. О.А.Казнина. Москва: ИМЛИ РАН, 2010. 608 с.

Горький М. «Несвоевременные мысли» и рассуждения о революции и культуре (1917-1918 гг.). Москва: МО Союза журналистов СССР. Ассоциация «Ротация» при участии МСП «Интерконтакт», 1990. $192 \mathrm{c}$.

Гройс Б. Утопия и обмен. Москва: Издательство «ЗНАК», 1993. $374 \mathrm{c.}$

Замятин Е.И. Сочинения. Москва: Книга, 1988. 575 с. (Из литературного наследия).

Кржижановский С.Д. Собрание сочинений: в VI т. T. V / сост., подгот. текста и коммент. В. Перельмутера. Москва: Б.С.Г. - Пресс; Санкт-Петербург: Симпозиум, 2010. 638 с.

Ланин Б.А. Анатомия литературной антиутопии // Общественные науки и современность. 1993. № 5. C. 154-163.

Лихачев Д.С. Поэтика древнерусской литературы. Москва: Наука, 1979. 360 с.

Мандельштам О. Конец романа // Эстетическое самосознание русской культуры. 20-е годы XX века: Антология / сост. Г.А.Белая. Москва: РГГУ, 2003. C. 91-95.

Поварницына Н.С. Свобода творчества и феномен хулиганства в русской лирике Серебряного века (В. Брюсов, В. Каменский, С. Есенин): Автореферат дисс. ... соискание ученой степени кандидата филологических наук. Ижевск - 2009.

Рымарь Н.T. Проблематизация художественных форм в 20-е годы XX века // Художественный язык литературы 20-х годов XX века. К 70-летию проф. В.П. Скобелева: [Сб. ст.] / Самар. гос. унт; научн. ред. Н.Т. Рымарь. Самар. гуманит. акад., 2001. С. 16-26.

Тынянов Ю. Русская литература современности // Седьмые Тыняновские чтения: материалы для обсуждения / ответ. ред. М.О. Чудакова. Рига - Москва, 1995-1996. С. 93.

Чудакова М. Новые работы: 2003-2006. Москва: Время, 2007. 560 с.

\section{References}

Belaja, G.A. (1989), Don Quixotes of the 20s: "The Pass" and the fate of his ideas, Sovetskij pisatel', Moscow, Russia.

In Search of a New Ideology: Sociocultural Aspects of the Russian Literary Process of the 1920s-1930s., (2010), O.A. Kaznina (ed), IMLI RAN, Moscow, Russia. 
Gor'kij, M. (1990), «Untimely thoughts» and discourses on Revolution and Culture (1917-1918), MO Sojuza zhurnalistov SSSR. Associacija «Rotacija» pri uchastii MSP «Interkontakt», Moscow, Russia.

Grojs, B. (1993), Utopia and Exchange, Izdatel'stvo «ZNAK», Moscow, Russia.

Zamjatin, E.I. (1988), Essays, Kniga, Moscow, Russia.

Krzhizhanovskij, S.D. (2010), Collected works: in VI vol., Vol. V., Perel'muter, V. B.S.G. - Press; Simpozium, Moscow, St. Petersburg, Russia.

Lanin, B.A. (1993), Anatomy of a Literary Dystopia, Obshhestvennye nauki i sovremennost', no 5, pp. 154-163.

Lihachev, D.S. (1979), Poetics of Old Russian literature, Nauka, Moscow, Russia.

Mandel'shtam, O. (2003), End of the novel, Aesthetic self-consciousness of Russian culture. The 20s of the twentieth century: An Anthology. Comp. G.A.Belaja, RGGU, Moscow, Russia, pp. 91-95.
Povarnicyna, N.S. (2009), Freedom of creativity and the phenomenon of hooliganism in Russian Lyrics of the Silver Age (V. Bryusov, V. Kamensky, S. Yesenin): Abstract of the diss. ... for the degree of candidate of philological sciences, Izhevsk, Russia.

Rymar', N.T. (2001), Problematization art forms in the 20th years of the XX century, Artistic language literature of the 20-ies of XX century. To the 70th anniversary of prof. V. P. Skobelev: [Collection of articles], Samar. gumanit. akad., pp. 16-26.

Tynyanov, Yu. (1995-1996), Russian literature of the present, Seventh Tynyanov readings: materials for discussion, Chudakova, M. (ed), Riga, Moscow, Russia.

Chudakova, M. (2007), New works 2003-2006, Vremja, Moscow, Russia.

Submitted: 20.01.2021

Revised: 03.03.2021

Accepted: 01.04.2021 